\title{
Lower myocardial perfusion in borderzones in the area at risk than out of the area at risk in acute myocardial infarction
}

\author{
Kaatje Goetschalckx ${ }^{1,2^{*}}$, Frank E Rademakers ${ }^{3}$, Jan Bogaert ${ }^{4,2}$, Attila Toth ${ }^{5}$, Béla Merkely ${ }^{5}$, Stefan Janssens ${ }^{1,3}$, \\ Piet Claus ${ }^{2,3}$
}

From 18th Annual SCMR Scientific Sessions

Nice, France. 4-7 February 2015

\section{Background}

Myocardial infarction (MI) leads to heart failure in a substantial number of patients. Investigation of perfusion in the infarct-adjacent segments can offer better insights into left ventricular remodeling. It is the aim of this study to compare myocardial blood flow (MBF) with cardiac magnetic resonance (CMR) in the infarct borderzones (BZ) and the remote myocardium (RM) in a large patient population in the acute phase of MI.

\section{Methods}

In this substudy of the NOMI-trial (ClinicalTrials.gov identifier: NCT01398384) using the placebo arm, 68 patients underwent CMR with restperfusion within 48 to 72 hours of acutely revascularized ST-elevation MI in a 1.5 tesla MR scanner (Achieva, Philips Medical Systems, The Netherlands). TIMI 2-3 flow was achieved in all patients after PCI. MBF was quantified using Fermi deconvolution with a dual bolus analysis technique (equal volumes of $0.0027 \mathrm{mmol} / \mathrm{kg}$ followed by $0.05 \mathrm{mmol} / \mathrm{kg}$ after a 20-s pause of contrast agent (Dotarem, Gd-DOTA, Guerbet, France)) in basal and midventricular short axis perfusion slices. A segmental model was applied on corresponding images of perfusion, late gadolinium enhancement (LGE) and T2-weighted images (T2W). The MBF of the infarct zone (IZ) was calculated as the mean perfusion of segments with LGE. The adjacent 30 degree segments were defined as BZ, and were also classified in BZ-inAAR and BZ-outAAR, depending on their location in- or outside the area at risk, respectively, as determined by T2W imaging. The MBF of the RM was calculated as the mean perfusion of the remaining segments. Apical slices seldomly included more than one myocardial zone and were excluded from analysis.

\section{Results}

One hundred thirty six slices were analyzed. Restperfusion was not significantly different in BZ and RM (resp. $0.50 \pm$ 0.22 and $0.51 \pm 0.23 \mathrm{ml} / \mathrm{g} / \mathrm{min}, \mathrm{p}=0.664)$. BZ-inAAR restperfusion however, was significantly lower than BZ-outAAR and RM perfusion (resp. $0.45 \pm .19,0.54 \pm .24$ and $0.51 \pm 0.23 \mathrm{ml} / \mathrm{g} / \mathrm{min}, \mathrm{p}<0.05)$ in the acute phase of MI. (cf. Table)

\section{Conclusions}

Myocardial restperfusion in infarct-adjacent segments is lower in- than outside the area at risk in acute MI. This regional myocardial perfusion inhomogeneity may impact subsequent LV remodeling, thereby offering new opportunities for targeted interventions.

\section{Funding}

No disclosures.

\section{Table 1}

\begin{tabular}{ccccc}
\hline$M B F(\mathrm{ml} / \mathrm{g} / \mathrm{min})$ & $\mathrm{IZ}$ & BZ-inAAR & BZ-outAAR & $\mathrm{RM}$ \\
\hline $\mathrm{n}=$ & 114 & 95 & 116 & 130 \\
\hline rest perfusion & $\mathbf{0 , 3 7} \hat{\mathbf{A}} \pm$ & $\mathbf{0 , 4 5} \hat{\mathbf{A}} \pm$ & $\mathbf{0 , 5 4 +}$ & $\mathbf{0 , 5 1} \hat{\mathbf{A}} \pm \mathbf{0 , 2 3}$ \\
& $\mathbf{0 , 1 9}$ & $\mathbf{0 , 1 9 ^ { * }}$ & $\mathbf{0 , 2 4 *}$ & $\mathbf{n s}^{*}$ \\
\hline
\end{tabular}

${ }^{*} p<0.05$ 


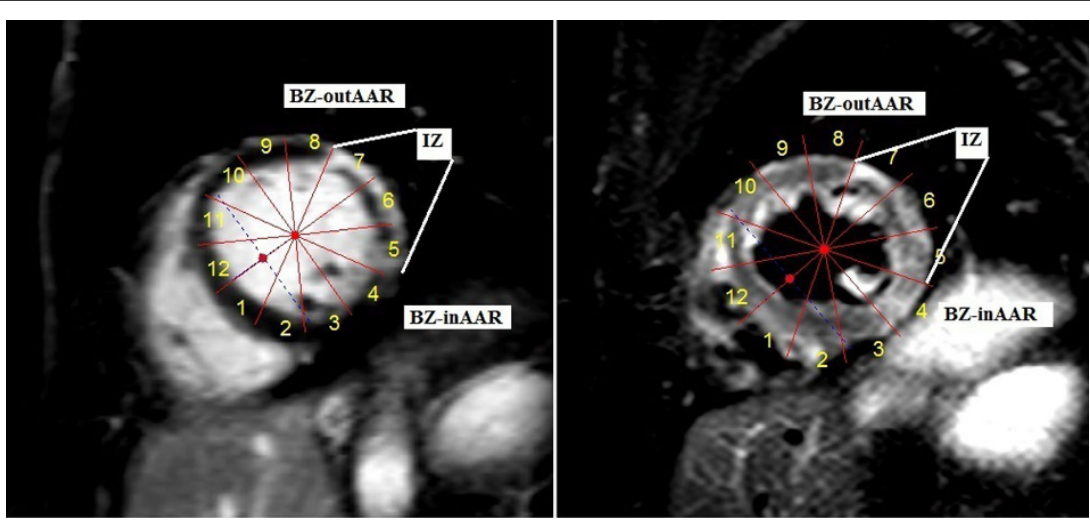

Figure 1 The left figure shows the late gadolinium enhancement midventricular short axis slice of an acute phase MI, with segments 5-7 defined as IZ (including microvascular obstruction), segments 4 and 8 as BZ and the remaining segments as RM. The right figure shows the corresponding T2-weighted image, with segment 4 defined as BZ-inAAR, and segment 8 as BZ-outAAR.

\section{Authors' details}

${ }^{1}$ Cardiovascular Diseases, University Hospital Leuven, Leuven, Belgium. ${ }^{2}$ Medical Imaging Research Center, University Hospitals Leuven, Leuven, Belgium. ${ }^{3}$ Department of Cardiovascular Sciences, KU Leuven, Leuven, Belgium. ${ }^{4}$ Department of Radiology, University Hospitals Leuven, Leuven, Belgium. ${ }^{5}$ Heart and Vascular Center, Semmelweis University, Budapest, Hungary.

Published: 3 February 2015

doi:10.1186/1532-429X-17-S1-P128

Cite this article as: Goetschalckx et al:: Lower myocardial perfusion in borderzones in the area at risk than out of the area at risk in acute myocardial infarction. Journal of Cardiovascular Magnetic Resonance 2015 17(Suppl 1):P128.

\section{Submit your next manuscript to BioMed Central} and take full advantage of:

- Convenient online submission

- Thorough peer review

- No space constraints or color figure charges

- Immediate publication on acceptance

- Inclusion in PubMed, CAS, Scopus and Google Scholar

- Research which is freely available for redistribution

Submit your manuscript at www.biomedcentral.com/submit 